\title{
COMPOSIÇÃO E FENOLOGIA DE ESPÉCIES HERBÁCEAS NATIVAS EM REFLORESTAMENTO HETEROGÊNEO
}

\author{
Rafael Arruda ${ }^{1}$, Camila Florencio ${ }^{2}$, Rodolfo Antônio de Figueiredo ${ }^{3}$, Maria Inês Salgueiro Lima ${ }^{4}$, \\ Nemésio Neves Batista Salvador ${ }^{5}$ \\ ${ }^{1}$ Acadêmico de Biologia, UNICEP, Araras, SP, Brasil - wk.arruda@itelefonica.com.br \\ ${ }^{2}$ Acadêmica de Biologia, UNICEP, Araras, SP, Brasil - ca_flor@yahoo.com.br \\ ${ }^{3}$ Biólogo, Dr., Coordenadoria Especial para o Meio Ambiente, UFSCar, Araras, SP, Brasil - rodolfo@ ufscar.br \\ ${ }^{4}$ Bióloga, Dr ${ }^{\mathrm{a}}$., Depto. de Botânica, UFSCar, Araras, SP, Brasil - ines@ufscar.br \\ ${ }^{5}$ Eng. Civil, Dr., Coordenadoria Especial para o Meio Ambiente, UFSCar, Araras, SP, Brasil - nemesio@ufscar.br
}

Recebido para publicação: 13/12/2007 - Aceito para publicação: 30/10/2008

\begin{abstract}
Resumo
Os reflorestamentos heterogêneos normalmente são feitos utilizando-se espécies vegetais de fácil germinação, rápido crescimento e que atendam à Resolução SMA 8/07. Tendo em vista serem escassas as informações sobre o componente herbáceo em reflorestamentos heterogêneos, o presente estudo teve por objetivo verificar a presença de plantas herbáceas de cerrado em um reflorestamento heterogêneo em São Carlos, estado de São Paulo. Foram levantadas as espécies herbáceas presentes em transectos estabelecidos em área de reflorestamento heterogêneo e em área próxima de cerrado stricto sensu. No reflorestamento heterogêneo foram registradas 25 espécies, pertencentes a sete famílias, e no cerrado foram registradas 35 espécies herbáceas, pertencentes a nove famílias. Dezessete espécies do cerrado também foram encontradas no reflorestamento. A floração das espécies de cerrado correlacionou-se positivamente com a temperatura média e a precipitação pluvial. No reflorestamento heterogêneo não foi encontrada correlação entre floração e variáveis meteorológicas. Conclui-se que a área de reflorestamento heterogêneo abriga grande parte da flora herbácea existente no cerrado da região, porém investigações de longo prazo ainda são necessárias para a compreensão adequada da dinâmica das plantas herbáceas em áreas de reflorestamento heterogêneo.

Palavras-chave: Reflorestamento heterogêneo; cerrado; herbáceas; levantamento florístico; floração.
\end{abstract}

\begin{abstract}
Composition and phenology of herbaceous species in heterogeneous reforestation. Heterogeneous reforestations are constituted mainly by plant species with easy germination, fast growing, and which follows the Resolução SMA 8/07. Due to the scarcity of information about the herbaceous component in heterogeneous reforestations, the present study aimed to verify the presence of cerrado (savannah) herbaceous species in a heterogeneous reforestation in São Carlos, São Paulo State, twenty five species belonging to seven families were found, in the heterogeneous reforestation whereas in the cerrado, 35 herbaceous species belonging to nine families were registered. Seventeen cerrado species were also found at the reforestation area. Cerrado species flowering was positively correlated to the average temperature and to pluvial precipitation. In reforestation, flowering was not correlated to climatic variables. In conclusion, the heterogeneous reforestation area sheltered the major number of cerrado herbaceous species, but long-term studies are still needed to a better comprehension of the flowering dynamics of herbaceous plants in heterogeneous reforestation areas.

Keywords: Heterogeneous reforestation; savannah; herbs; floristic survey; flowering.
\end{abstract}

\section{INTRODUÇÃO}

Os reflorestamentos heterogêneos utilizando espécies arbóreas nativas são realizados com os objetivos de recomposição de áreas degradadas ou de produção de insumos florestais (KAGEYAMA; CASTRO, 1989). A atividade de reflorestamento é de interesse público, uma vez que a recuperação do ambiente traz vários benefícios tanto para as áreas naturais como para as comunidades humanas (GALVÃO, 2000). Os reflorestamentos heterogêneos, ou seja, aqueles que utilizam uma ampla variedade 
de espécies, são importantes para a regeneração de ambientes, preservando espécies vegetais e fornecendo recursos para a fauna, além de atuarem no controle da poluição atmosférica, na amenização climática e na melhora da drenagem, recuperando a produção de água em microbacias, e de poderem ser utilizados para recreação, atividades educacionais e pesquisas científicas (SOARES, 1998; FIGUEIREDO et al., 2007).

Idealmente, os reflorestamentos devem ser feitos com espécies vegetais que ocorram em locais com as mesmas características da área a ser recuperada (GALVÃO, 2000). No entanto, as empresas fornecedoras de mudas para reflorestamento trabalham com uma variedade limitada de espécies vegetais nativas, normalmente aquelas de fácil germinação e rápido crescimento e que atendam à Resolução SMA 8/07 (SMA, 2007). A Resolução SMA 47/03 tem por finalidade a "orientação para o reflorestamento heterogêneo de áreas degradadas", mas não traz indicações de espécies de cerrado para reflorestamentos heterogêneos da região Sudeste do Brasil. Portanto, a maioria das espécies encontrada nos viveiros do interior do estado de São Paulo é de áreas úmidas, uma vez que normalmente os reflorestamentos visam à recuperação de mata ciliar em propriedades rurais (DURIGAN; SILVEIRA, 1999; BARBOSA, 2006). Apesar desse problema já ter sido levantado há muitos anos (KAGEYAMA, 1990), só recentemente os diplomas legais pertinentes ao tema reflorestamento estão admitindo essa dificuldade de inclusão de espécies nativas do bioma cerrado, além de alguns outros, nos reflorestamentos heterogêneos. A Resolução SMA 8/2007, por exemplo, estabelece no artigo $6^{\circ}$ que "em áreas de ocorrência (...) de savana florestada (cerradão), a recuperação florestal deverá atingir, no período previsto em projeto, o mínimo de 80 (oitenta) espécies florestais nativas de ocorrência regional", e o artigo 13 da mesma Resolução diz que os órgãos governamentais e não-governamentais têm o dever de "capacitar produtores de sementes e mudas para a produção com diversidade florística e genética" (SMA, 2007).

O campus da UFSCar possui uma reserva de cerrado stricto sensu com cerca de 124 ha, uma área de reflorestamento homogêneo de eucalipto (Eucalyptus spp., Myrtaceae), uma área de reflorestamento homogêneo de pinus (Pinus elliottii Engelm, Pinaceae) e uma área de reflorestamento heterogêneo com espécies nativas implantado entre 2003 e 2005, posicionado ao redor do córrego do Espraiado (tributário do córrego Monjolinho, que é uma das fontes de abastecimento de água para a cidade de São Carlos). A área onde o reflorestamento heterogêneo foi estabelecido consistia anteriormente em um cerrado que foi transformado em pasto de braquiária pela antiga fazenda e assim permaneceu por vários anos, sofrendo intenso gradeamento.

Não existe qualquer informação publicada sobre a composição de plantas herbáceas em áreas de reflorestamento heterogêneo no Brasil. Em âmbito internacional, somente um estudo investiga as espécies herbáceas em área de reflorestamento nos Estados Unidos, indicando que a composição desse estrato herbáceo se altera profundamente com o passar do tempo, abrigando cada vez mais espécies nativas da região (LEARY; HOWES-KEIFFER, 2004). Além disso, até o momento não existem estudos publicados sobre a composição de espécies herbáceas que ocorrem em áreas de cerrado stricto sensu no município de São Carlos. Apenas um estudo levantou as espécies herbáceas e subarbustivas que emergiram após fogo em uma área originalmente recoberta por cerradão (SOARES; LIMA, 2000). Em cidade próxima, Itirapina, foi realizado um levantamento de espécies de áreas úmidas e secas de cerrado (TANNUS et al., 2007). Os demais levantamentos florísticos realizados em São Carlos tratam de lianas, arbustos e espécies arbóreas (HORA; SOARES, 2002; SILVA; SOARES, 2003; SOARES et al., 2006). Um levantamento das espécies da flora fanerogâmica do cerrado da UFSCar foi realizado por Cátia Urbanetz em 2002, em sua monografia de Bacharelado (ainda não publicada).

Os objetivos do presente estudo são levantar as espécies herbáceas presentes no reflorestamento heterogêneo implantado no campus da UFSCar em 2005, assim como registrar as épocas de floração das espécies encontradas.

\section{MATERIAL E MÉTODOS}

O trabalho de campo foi realizado no campus da Universidade Federal de São Carlos (UFSCar) $-21^{\circ} 58^{\prime}-22^{\circ} 00^{\prime} \mathrm{S}$ e $47^{\circ} 51^{\prime}-47^{\circ} 52^{\prime} \mathrm{W}, 815-895$ metros de altitude. A região apresenta clima temperado quente com inverno seco (estação seca de abril a setembro) e verão chuvoso (estação chuvosa de outubro a março), classificado como Cwa, segundo o sistema de Köeppen (1948). A temperatura média anual varia de $20,8^{\circ} \mathrm{C}$ a $21,7^{\circ} \mathrm{C}$, enquanto que a pluviosidade média anual varia de 1.138 a $1.593 \mathrm{~mm}$. Os tipos 
de solo são Latossolo Vermelho-Amarelo Álico na área de reflorestamento e Latossolo Vermelho Amarelo Distrófico na área de cerrado (SANTOS et al., 1996).

A Universidade Federal de São Carlos (UFSCar) tem seu campus situado na antiga Fazenda Tranchan, adquirida pela Prefeitura Municipal de São Carlos em 1968 e posteriormente doada para a Universidade. A vegetação nativa da região é o cerrado, que foi praticamente todo eliminado pelas atividades daquela fazenda. Em 1993, a UFSCar criou a Coordenadoria Especial para o Meio Ambiente (CEMA), com o objetivo de promover a gestão sustentável dos ambientes existentes na instituição, e hoje já existem várias áreas de cerrado em recuperação no campus. Entre os anos de 2003 e 2005, a CEMA/UFSCar reflorestou áreas do campus ocupadas por gramíneas exóticas, sendo que esse reflorestamento heterogêneo foi realizado com mudas adquiridas de viveiros da região. As espécies vegetais fornecidas foram as pertencentes aos ambientes mais úmidos (Floresta Estacional Semidecídua e Floresta Ombrófila) e ao cerrado. Não existem dados sobre a densidade das árvores plantadas no reflorestamento, mas visualmente é possível perceber que as árvores estão distantes umas das outras, permitindo que os raios solares atinjam diretamente o solo. Embora a área de cerrado tenha uma cobertura arbórea mais densa, raramente suas copas se tocam, e o nível de insolação que atinge o solo é significativo. A serapilheira é visivelmente maior na área de cerrado do que na de reflorestamento, sendo este último dominado por capim-braquiária (Brachiaria decumbens).

Em agosto de 2006, um incêndio de origem antrópica de grandes proporções devastou uma grande parte da área de cerrado e de reflorestamento heterogêneo da UFSCar, mas verificou-se que uma pequena faixa dessas áreas escapou do incêndio e ainda apresentava a vegetação original. Assim sendo, estabeleceu-se um transecto de $200 \mathrm{~m}^{2}(200 \times 1 \mathrm{~m})$ na faixa não afetada pelo incêndio na área de reflorestamento heterogêneo, e todas as espécies herbáceas encontradas foram coletadas e identificadas. À guisa de comparação com a flora herbácea nativa da região de estudo (cerrado stricto sensu), dois outros transectos de $200 \mathrm{~m}^{2}$ (cada um de $200 \mathrm{x} 1 \mathrm{~m}$ ) foram estabelecidos na pequena área de cerrado que também escapou do fogo, distante cerca de $50 \mathrm{~m}$ do reflorestamento heterogêneo. Também nesses transectos foram coletadas e identificadas todas as espécies herbáceas. $\mathrm{Na}$ área de reflorestamento, o transecto foi alocado a cerca de $310 \mathrm{~m}$ do córrego do Monjolinho, local com uma declividade de 8 a 13\%, enquanto que o transecto da área de cerrado distava cerca de $390 \mathrm{~m}$ do córrego do Fazzari, em uma declividade de 3 a $8 \%$.

As coletas das espécies herbáceas ocorreram entre setembro de 2006 e agosto de 2007. Os exemplares coletados foram preparados de acordo com a metodologia usual (FIDALGO e BONONI, 1984) e, para a identificação dos exemplares, utilizou-se bibliografia específica para famílias, gêneros e espécies, além de consulta ao herbário da UFSCar. Também foi registrada a época de floração de cada espécie, que foi correlacionada à precipitação pluvial e à temperatura média. Os dados dessas variáveis climáticas para a região de São Carlos foram fornecidos pela Embrapa Pecuária Sudeste, cuja estação climatológica se encontra nas coordenadas geográficas $21^{\circ} 57^{\prime} \mathrm{S}$ e $47^{\circ} 50^{\prime} \mathrm{W}$, distante cerca de $10 \mathrm{~km}$ da área de estudo. Utilizou-se o coeficiente de correlação de Spearman, $r_{s}$, cujos valores de significância se encontram em Zar (1996).

\section{RESULTADOS E DISCUSSÃO}

$\mathrm{Na}$ área de reflorestamento heterogêneo foram identificadas 25 espécies vegetais herbáceas, pertencentes a sete famílias (Tabela 1). Asteraceae foi a família que apresentou maior número de espécies.

$\mathrm{Na}$ área de cerrado foram coletadas e identificadas 35 espécies herbáceas, pertencentes a nove famílias (Tabela 2). No cerrado, a família Fabaceae apresentou o maior número de espécies, e as famílias Euphorbiaceae e Lamiaceae foram encontradas somente nessa área.

Dezessete espécies herbáceas, das 25 registradas no reflorestamento heterogêneo, também foram encontradas no cerrado, indicando que a maioria das colonizadoras proveio da dispersão de espécies presentes no cerrado. Soares e Lima (2000) levantaram a presença de 33 espécies herbáceas e subarbustivas ao longo de cinco anos seguintes a uma queimada em área de cerradão no município de São Carlos. Dentre as plantas levantadas na área de cerradão, cinco gêneros também foram registrados no presente estudo: Diodia sp., Hyptis eriophylla, Melinis minutiflora, Sida spp. e Stylosanthes guianensis (SOARES; LIMA, 2000). 
Tabela 1. Famílias e espécies herbáceas amostradas na área de reflorestamento heterogêneo.

Table 1. Families and herbaceous species sampled in the heterogeneous reforestation area.

\begin{tabular}{|c|c|c|}
\hline Família & Espécie & Nome comum \\
\hline \multirow[t]{8}{*}{ Asteraceae } & Achyrocline satureioides Gardner & Macela-do-campo \\
\hline & Bidens alba DC. & Picão-preto \\
\hline & Chaptalia integerrima (Vell.) Burkart & Língua-de-vaca \\
\hline & Conyza bonariensis (L.) Cronquist & Erva-lanceta \\
\hline & Emilia sonchifolia (L.) DC. & Serralha \\
\hline & Eupatorium sp. & Eupatório \\
\hline & Orthopappus angustifolius Gleason & Erva-grossa \\
\hline & Pterocaulon lanatum Kuntze & Branqueja \\
\hline \multirow[t]{2}{*}{ Cyperaceae } & Cyperus brevifolius (Rottb.) Hassk. & Junquinho \\
\hline & Fimbristylis autumnalis Roem e Shult & Falso-alecrim \\
\hline \multirow[t]{4}{*}{ Fabaceae } & Chamaecrista rotundifolia (Pers.) Greene & Erva-de-coração \\
\hline & Mimosa capillipes Benth & Dormideira \\
\hline & Stylosanthes guianensis (Aubl.) Sw. & Estilosante \\
\hline & Zornia latifolia DC. & Alfafa-do-campo \\
\hline \multirow[t]{3}{*}{ Malvaceae } & Sida glaziovii K. Schum. & Malva-guaxima \\
\hline & Sida linifolia Cav. & Malva-fina \\
\hline & Waltheria douradinha A. St.-Hil. & Douradinha-do-campo \\
\hline \multirow[t]{4}{*}{ Poaceae } & Brachiaria decumbens Stapf & Capim-braquiária \\
\hline & Chloris polydactyla SW. & Capim-pé-de-galinha \\
\hline & Digitaria insularis (L.) Fedde & Capim-colchão \\
\hline & Melinis minutiflora P. Beauv. & Capim-gordura \\
\hline \multirow[t]{3}{*}{ Rubiaceae } & Diodia teres Walter & Mata-pasto \\
\hline & Mitracarpus hirtus (L.) DC. & Poaia \\
\hline & Richardia scabra L. & Poaia-do-cerrado \\
\hline Verbenaceae & Stachytarpheta cayennensis (Rich.) J. Vahl & Gervão \\
\hline
\end{tabular}

Em uma cidade próxima a São Carlos, Itirapina ( $22^{\circ} 10^{\prime} \mathrm{S}$ de latitude e $47^{\circ} 45^{\prime} \mathrm{W}$ de longitude), Tannus et al. (2006) encontraram 330 espécies herbáceo-subarbustivas. Destas, 13 foram registradas pelo presente estudo na área de reflorestamento e 12 na área de cerrado. Batalha e Mantovani (2000), em trabalho realizado em área natural de cerrado no interior do estado de São Paulo, Santa Rita do Passa Quatro $\left(21^{\circ} 41^{\prime} \mathrm{S}, 47^{\circ} 28^{\prime} \mathrm{W}\right)$, registraram a presença de 236 espécies no componente herbáceosubarbustivo, das quais 11 foram encontradas na área de reflorestamento e 11 na área de cerrado do presente estudo.

Quatro espécies herbáceas encontradas no presente estudo são exóticas: Emilia sonchifolia (serralha), originária da Ásia, e as gramíneas Brachiaria decumbens (capim-braquiária), Melinis minutiflora (capim-gordura) e Panicum repens (capim-torpedo), todos originários da África (e.g. LORENZI, 2000). As três primeiras espécies foram encontradas tanto no reflorestamento heterogêneo como no cerrado stricto sensu, enquanto que o capim-torpedo foi registrado somente na área de cerrado. Soares e Lima (2000) também registraram a presença de Melinis minutiflora na área de cerradão em São Carlos.

A vegetação herbácea natural presente nas savanas sul-americanas foi substituída por gramíneas africanas quando de sua conversão em pastagens para gado, tendo sido utilizados principalmente o gênero Brachiaria (LOPEZ-HERNANDEZ et al., 2005). Durigan et al. (2007) mostraram que a presença de gramíneas invasoras é uma das ameaças mais frequentes em áreas de cerrado do interior do estado de São Paulo. O manejo da área de reflorestamento heterogêneo na UFSCar, portanto, deve incluir a diminuição das populações das gramíneas exóticas e a manutenção das populações das herbáceas nativas, uma vez que elas fazem parte do domínio do cerrado.

Todas as plantas herbáceas encontradas no reflorestamento heterogêneo floresceram durante o período de estudo, assim como ocorreu com as espécies registradas no cerrado (Figura 1).

Utilizando-se os dados de precipitação pluvial e de temperatura média para a região de São Carlos no período de estudo (Figura 2A), não foram encontradas correlações significativas entre a floração das espécies encontradas no reflorestamento heterogêneo com a temperatura média $\left(r_{s}=0,38\right.$, $0,20<\mathrm{p}<0,25)$ e com a pluviosidade $\left(\mathrm{r}_{\mathrm{s}}=0,27,0,20<\mathrm{p}<0,25\right)$. Quanto às espécies registradas no cerrado, 
foi encontrada correlação positiva significativa entre a floração e a temperatura média $\left(r_{s}=0,75, p<0,05\right)$, mas não foi verificada correlação entre a floração e a pluviosidade $\left(r_{s}=0,45,0,05<p<0,10\right)$.

Tabela 2. Famílias e espécies herbáceas amostradas na área de cerrado.

Table 2. Families and herbaceous species sampled in the cerrado area.

\begin{tabular}{|c|c|c|}
\hline Família & Espécie & Nome comum \\
\hline \multirow[t]{3}{*}{ Asteraceae } & Chaptalia integerrima (Vell.) Burkart & Língua-de-vaca \\
\hline & Chaptalia nutans (L.) Polak & Língua-de-vaca-miúda \\
\hline & Emilia sonchifolia (L.) DC. & Serralha \\
\hline \multirow[t]{4}{*}{ Cyperaceae } & Bulbostylis capillaris Kunth & Alecrim-da-praia \\
\hline & Cyperus brevifolius (Rottb.) Hassk. & Junquinho \\
\hline & Cyperus polystachyos Rottb & Três-quinas \\
\hline & Rhynchospora aurea Vahl. & Capim-navalha \\
\hline Euphorbiaceae & Croton glandulosus Blanco & Gervão-branco \\
\hline \multirow[t]{10}{*}{ Fabaceae } & Chamaecrista nictitans Moench & Falsa-dormideira \\
\hline & Chamaecrista rotundifolia (Pers.)Greene & Erva-de-coração \\
\hline & Crotalaria micans Link & Chocalho \\
\hline & Centrosema pubescens Benth. & Feijãozinho \\
\hline & Desmodium adscendens DC. & Carrapicho \\
\hline & Desmodium incanum DC. & Carrapicho \\
\hline & Mimosa capillipes Benth. & Dormideira \\
\hline & Stylosanthes guianensis (Aubl.) Sw. & Estilosante \\
\hline & Stylosanthes viscosa (L.) Sw. & Meladinha \\
\hline & Zornia latifolia DC. & Alfafa-do-campo \\
\hline \multirow[t]{2}{*}{ Lamiaceae } & Hyptis atrorubens Poit. & Hortelã-brava \\
\hline & Hyptis eriophylla Pohl & Hortelã-do-cerrado \\
\hline \multirow[t]{5}{*}{ Malvaceae } & Peltaea speciosa Standl & Malva \\
\hline & Sida glaziovii K. Shum. & Malva-guaxima \\
\hline & Sida linifolia Cav. & Malva-fina \\
\hline & Sida santaremensis Monteiro & Guanxuma \\
\hline & Waltheria douradinha A. St.-Hil. & Douradinha-do-campo \\
\hline \multirow[t]{5}{*}{ Poaceae } & Andropogon leucostachyus Kunth & Campim-membeca \\
\hline & Brachiaria decumbens Stapf & Capim-braquiária \\
\hline & Digitaria insularis (L.) Fedde & Capim-pé-de-galinha \\
\hline & Melinis minutiflora $\mathrm{P}$. Beauv. & Capim-gordura \\
\hline & Panicum repens $\mathrm{L}$. & Capim-torpedo \\
\hline \multirow[t]{4}{*}{ Rubiaceae } & Diodia alata Nees e Mart. & Mata-pasto \\
\hline & Mitracarpus hirtus (L.) DC. & Poaia \\
\hline & Richardia scabra L. & Poaia-do-cerrado \\
\hline & Spermacoce latifolia Aubl. & Erva-de-lagarto \\
\hline Verbenaceae & Stachytarpheta cayennensis (Rich.) Vahl. & Gervão \\
\hline
\end{tabular}

Nos meses mais secos (julho e agosto), nenhuma espécie floresceu em qualquer das áreas, sendo que o pico de floração no reflorestamento heterogêneo ocorreu no final da estação seca (mês de setembro) e o pico de floração no cerrado ocorreu no início da estação chuvosa (outubro).

A fim de verificar se a ausência de correlações significativas foi devido ao efeito das condições meteorológicas dos meses em que foi desenvolvido o estudo, o que pode ter mascarado uma resposta fenológica aos valores médios que ocorrem historicamente ao longo dos anos na região, também foram utilizados os dados históricos de um período de 54 anos de temperatura média e pluviosidade para a região de São Carlos (Figura 2B). Nesse caso, as correlações entre floração das espécies de cerrado foram significativas tanto para a temperatura média $\left(\mathrm{r}_{\mathrm{s}}=0,72, \mathrm{p}<0,05\right)$ como para a precipitação pluvial $\left(\mathrm{r}_{\mathrm{s}}=\right.$ $0,76, \mathrm{p}<0,05)$. Porém, para as espécies presentes no reflorestamento heterogêneo, a correlação entre a floração e a temperatura média e a precipitação pluvial continuaram não significativas $\left(\mathrm{r}_{\mathrm{s}}=0,39\right.$ para temperatura média e $\mathrm{r}_{\mathrm{s}}=0,53$ para pluviosidade). 


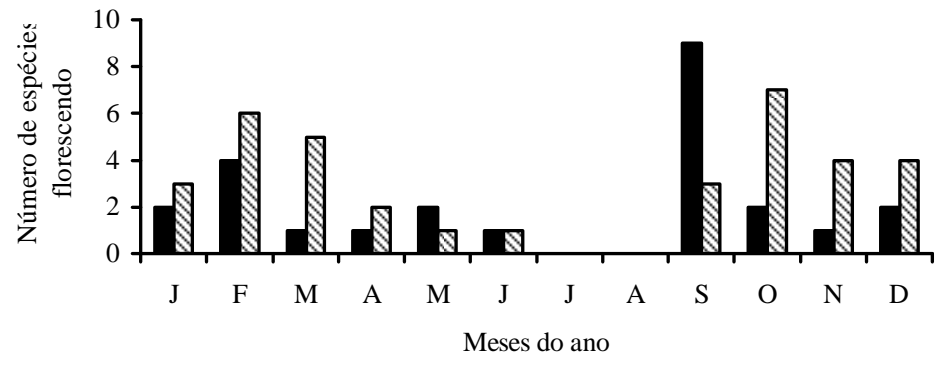

Reflorestamento $\mathbf{Q}$ Cerrado

Figura 1. Número de espécies florescendo em áreas de reflorestamento heterogêneo e de cerrado. São Carlos, SP. Legenda: $\mathrm{J}$ - janeiro, $\mathrm{F}$ - fevereiro, ..., $\mathrm{N}$ - novembro e D - dezembro.

Figure 1. Number of species flowering in areas of heterogeneous reforestation and cerrado. São Carlos, SP. Legend: J - January, F - February, ..., N - November and D - December.
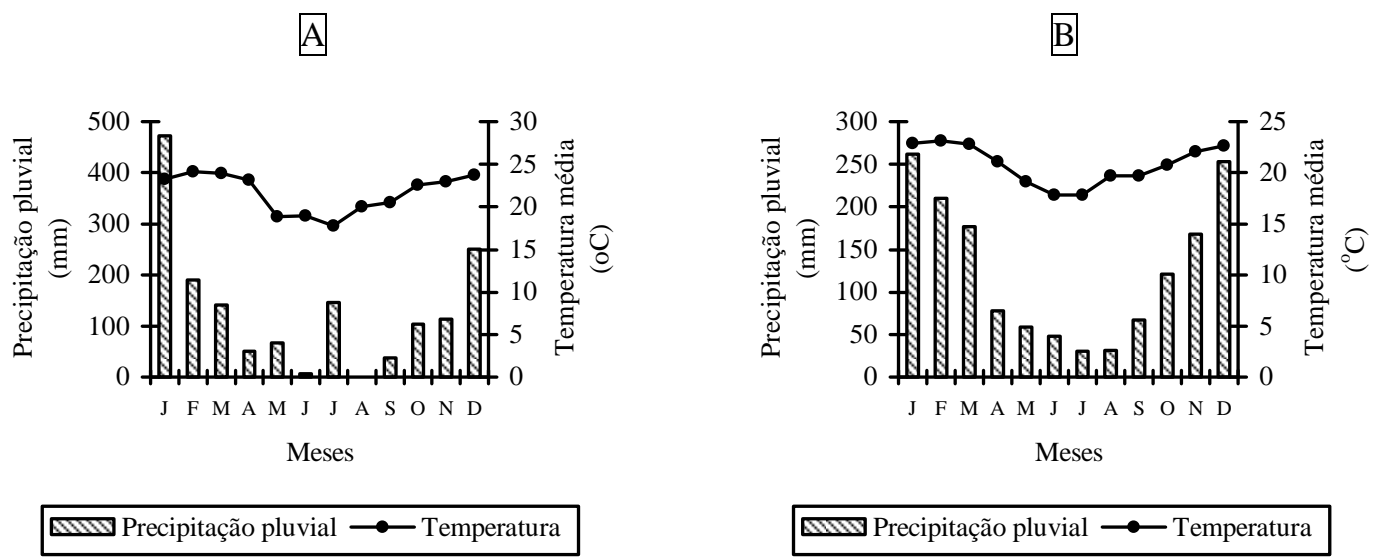

Figura 2. Precipitação pluvial e temperatura média para a região. (A) Dados do período de estudo; (B) dados históricos dos últimos 90 anos para a região.

Figure 2. Pluvial precipitation and average temperature for the region. (A) Data of the study period; (B) historical data from 54 years for the region.

Não existem estudos sobre a fenologia de espécies herbáceas em áreas de reflorestamento heterogêneo. No entanto, alguns estudos verificaram as épocas de floração de herbáceas em cerrado no estado de São Paulo (MANTOVANI; MARTINS, 1988; BATALHA et al., 1997; BATALHA; MANTOVANI, 2000; TANNUS et al., 2006). Em todos esses estudos, a comunidade herbácea apresentou floração distribuída por todo o ano, porém com grande diminuição de espécies com flores nos meses de junho e julho, auge da estação seca. Batalha; Mantovani (2000) mostraram que a proporção de espécies em floração aumenta até fevereiro e diminui até agosto. Tannus et al. (2006) verificaram que as espécies herbáceo-subarbustivas atingiram picos de floração na estação chuvosa, estando a floração correlacionada positivamente à temperatura média. Em área de cerrado em Goiás, Batalha; Martins (2004) verificaram uma correlação positiva significativa entre a floração do componente herbáceo com a precipitação pluvial.

Na estação seca, a queda no número de espécies em floração possivelmente é mais acentuada devido à falta de água no solo, o que sugere que a falta de chuvas pode ser um fator limitante para a maioria das espécies nesse ambiente (MUNHOZ; FELFILI, 2005). No clima semiárido do Nordeste 
brasileiro, a maioria das espécies vegetais de cerrado e de caatinga também floresce no período chuvoso (PEREIRA et al., 1989; COSTA et al., 2004). Têm-se admitido que as espécies herbáceo-subarbustivas, de modo geral, apresentam ciclos de vida limitados pela disponibilidade hídrica devido à presença de sistemas subterrâneos superficiais (RACHID, 1947; MONASTIERO; SARMIENTO, 1976; SARMIENTO, 1983; MANTOVANI; MARTINS, 1988).

No presente estudo, no entanto, correlações significativas entre as variáveis meteorológicas e a floração de espécies herbáceas somente foram encontradas na área de cerrado, enquanto que para as espécies presentes no reflorestamento heterogêneo não houve correlação da época de floração com a precipitação pluvial e com a temperatura média. Não foram encontrados estudos que indicassem quais as possíveis causas de os fatores meteorológicos não influenciarem a floração de plantas herbáceas em reflorestamentos heterogêneos. Uma hipótese que poderia ser testada em uma futura pesquisa seria que a utilização de espécies vegetais arbóreas de diversos estádios de sucessão e o manejo empregado em tais áreas alteram as condições microclimáticas e, consequentemente, influenciam os padrões fenológicos da comunidade de plantas herbáceas ali presentes.

\section{CONCLUSÕES}

O reflorestamento heterogêneo da UFSCar, mesmo tendo sido composto por espécies arbóreas de áreas úmidas, apresentou $71,4 \%$ do número de espécies e 77,8\% do número de famílias de plantas herbáceas que ocorriam em área próxima de cerrado stricto sensu, indicando uma possível colonização por espécies herbáceas de áreas próximas de cerrado.

As plantas herbáceas em regeneração na área em que foi efetuado o reflorestamento heterogêneo produziram flores ao longo de quase todo o ano, o que pode contribuir com recursos alimentares (néctar, pólen e tecidos florais) às espécies de insetos e pequenos vertebrados que utilizam o reflorestamento e as áreas próximas. No entanto, futuros estudos ainda são necessários para melhor embasar essa hipótese. Além disso, as espécies herbáceas que forem zoofílicas e zoocóricas poderão oferecer recursos alimentares para animais polinizadores e dispersores de sementes, permitindo uma conectividade biológica com as populações presentes nos ecossistemas circundantes ao reflorestamento heterogêneo.

A ausência de correlação significativa entre o número de espécies em floração e as variáveis meteorológicas na área de reflorestamento heterogêneo, diferentemente do que foi observado para a área de cerrado, podem estar simplesmente refletindo as diferenças florísticas entre as áreas ou, também, podem indicar influência do microambiente. De qualquer forma, ainda não é possível tecer considerações mais profundas sobre a história de vida das espécies do estrato herbáceo nesse ambiente, necessitando de estudos mais aprofundados. Investigações de longo prazo ainda são necessárias para a compreensão adequada da dinâmica de floração das plantas herbáceas em áreas de reflorestamento heterogêneo.

Apesar de não ter sido possível, com o presente estudo, verificar a influência das espécies arbóreas utilizadas no reflorestamento em relação ao componente herbáceo, a presença de herbáceas nativas de cerrado é um importante indício de que a área poderá apresentar espécies arbustivas e arbóreas pertencentes à formação florestal nativa (cerrado, cerradão ou Floresta Estacional Semidecídua), assim como já foi verificado em estudos realizados em áreas degradadas por mineração (ALMEIDA e SÁNCHEZ, 2005; GUEVARA et al., 2005).

\section{AGRADECIMENTOS}

Os autores agradecem a dois revisores anônimos que fizeram importantes melhorias na versão preliminar do manuscrito.

\section{REFERÊNCIAS}

ALMEIDA, R. O. P. O.; SÁNCHEZ, L. E. Revegetação de áreas de mineração: critérios de monitoração e avaliação do desempenho. Revista Árvore, Viçosa, MG, v. 29, p. 47-54, 2005.

BARBOSA, L. M. (coord.). Manual para recuperação de áreas degradadas do Estado de São Paulo: matas ciliares do interior paulista. São Paulo: Instituto de Botânica, 2006. 
BATALHA, M. A.; ARAGAKI, S; MANTOVANI, W. Variações fenológicas das espécies do cerrado em Emas (Pirassununga, SP). Acta Botanica Brasilica, Porto Alegre, v. 11, p. 61-78, 1997.

BATALHA, M. A.; MANTOVANI, W. Reproductive phenological patterns of cerrado plant species at the Pé-de-Gigante Reserve (Santa Rita do Passa Quatro, SP, Brazil): a comparasion between herbaceous and wood floras. Revista Brasileira de Biologia, Rio de Janeiro, v. 60, p. 129-145, 2000.

BATALHA, M. A.; MARTINS, F. R. Reproductive phenology of the cerrado plant community in Emas National Park (central Brazil). Australian Journal of Botany, Melbourne, v. 52, p. 149-161, 2004.

COSTA, I. R.; ARAÚJO, F. S.; LIMA-VERDE, L. W. Flora e aspectos auto-ecológicos de um encrave de cerrado na Chapada do Araripe, nordeste do Brasil. Acta Botanica Brasilica, Porto Alegre, v. 18, p. 759770, 2004.

DURIGAN, G.; SILVEIRA, E. R. Recomposição da mata ciliar em domínio de cerrado, Assis, SP. Scientia Forestalis, Piracicaba, n. 56, p. 135-144, 1999.

DURIGAN, G.; SIQUEIRA, M. F.; FRANCO, G. A. D. C. Threats to the cerrado remnants of the State of São Paulo, Brazil. Scientia Agricola, Piracicaba, v. 64, p. 355-363, 2007.

FIDALGO, O.; BONONI, V. L. R. Técnicas de coleta, preservação e herborização de material botânico. São Paulo: Instituto de Botânica, 1984. 62 p.

FIGUEIREDO, R. A.; MATTIAZZI, B; KLEFASZ, A. Florestas urbanas: novo paradigma para o turismo sustentável e para a educação ambiental. In: CASTELLANO, E. G.; FIGUEIREDO, R. A.; CARVALHO, C. L. (Eco)turismo e educação ambiental: diálogo e prática interdisciplinar, p. 219-229. São Carlos: Rima, 2007.

GALVÃO, A. P. M. Reflorestamento de propriedades rurais para fins produtivos e ambientais. Brasília: Embrapa Comunicação para Transferência de Tecnologia, 2000. 351 p.

GUEVARA, R.; ROSALES, J.; SANOJA, E. Vegetación pionera sobre rocas, un potencial biológico para la revegetación de áreas degradadas por la minería de hierro. Interciencia, Caracas, v. 30, p. 644-651, 2005.

HORA, R. C.; SOARES, J. J. Estrutura fitossociológica da comunidade de lianas em uma floresta estacional semidecidual na Fazenda Canchim, São Carlos, SP. Revista Brasileira de Botânica, São Paulo, v. 23, p. 323-329, 2002.

LEARY, C. I.; HOWES-KEIFFER, C. Comparison of standing vegetation and seed bank composition one year following hardwood reforestation in southwestern Ohio. Ohio Journal of Science, Columbus, v. 104, p. 20-28, 2004.

KAGEYAMA, P. Y. Plantações de essências nativas: florestas de proteção e reflorestamentos mistos. Documentos Florestais, Piracicaba, n. 8, p. 1-9, 1990.

KAGEYAMA, P. Y.; CASTRO, C. F. A. Sucessão secundária, estrutura genética e plantações de espécies arbóreas nativas. IPEF, Piracicaba, n. 41/42, p. 83-93, 1989.

KÖEPPEN, W. Climatologia: con un estudio de los climas de la tierra. México: Fondo de Cultura Económica, 1948. 478 p.

LOPEZ-HERNANDEZ, D.; HERNANDEZ-HERNANDEZ, R. M.; BROSSARD, M. Recent use history of South American savannah land. Case studies in the Orinoco savannas. Interciencia, Caracas, v. 30, p. 623-630, 2005.

LORENZI, H. Plantas daninhas do Brasil. Nova Odessa: Plantarum, 2000. 608 p.

MANTOVANI, W; MARTINS, F. R. Variações fenológicas das espécies do cerrado da Reserva Biológica de Moji Guaçu, Estado de São Paulo. Revista Brasileira de Botânica, São Paulo, v. 11, p. 101-112, 1988. 
MONASTIERO, M.; SARMIENTO, G. Phenological strategies of plant species in the tropical savanna and semi-deciduous forest of the Venezuelan Llanos. Journal of Biogeography, Oxford, v. 3, p. 325$356,1976$.

MUNHOZ, C. B. R.; FELFILI, J. M. Fenologia do estrato herbáceo-subarbustivo de uma comunidade de campo sujo na Fazenda Água Limpa no Distrito Federal, Brasil. Acta Botanica Brasílica, Porto Alegre, v. 19, p. 979-988, 2005.

PEREIRA, R. M. A.; ARAÚJO FILHO, J. A. A.; LIMA, R. V.; PAULINO, F. D. G.; LIMA, A. O. N.; ARAÚJO, Z. B. Estudos fenológicos de algumas espécies lenhosas e herbáceas da caatinga. Ciência Agronômica, Fortaleza, v. 20, p. 11-20, 1989.

RACHID, M. Transpiração e sistemas subterrâneos da vegetação de verão dos campos de cerrado de Emas. Boletim Botânico da Universidade de São Paulo, São Paulo, v. 80, p. 5-140, 1947.

SANTOS, J. E.; PAESE, A.; PIRES, J. S. R. Unidades da paisagem (biótopos) do campus da UFSCar. São Carlos: Ed. UFSCar, 1996. 14 p.

SARMIENTO, G. Patterns of specific phenological diversity in the grass communit of the Venezuelan tropical savannas. Journal of Biogeography, Oxford, v. 10, p. 373-391, 1983.

SILVA, L. A.; SOARES, J. J. Composição florística de um fragmento de floresta estacional semidecídua no município de São Carlos - SP. Revista Árvore, Viçosa, MG, v. 27, p. 647-656, 2003.

SECRETARIA DO MEIO AMBIENTE DO ESTADO DE SÃO PAULO (SMA). Resolução 8, de 7 de março de 2007. Disponível em: <http://www.ambiente.sp.gov.br/legislacao/estadual/resolucao/2007_res _est_sma_08.pdf $>$. Acesso em: 20/09/2007.

SOARES, J. J.; LIMA, M. I. S. Sucessão pós-fogo de espécies herbáceas e sub-arbustivas em cerradão. Vegetalia, São José do Rio Preto, v. 34, p. 29-43, 2000.

SOARES, J. J.; SOUZA, M. H. A. O.; LIMA, M. I. S. Twenty years of post-fire plant sucession in a 'cerrado', São Carlos, SP, Brazil. Brazilian Journal of Biology, São Carlos, v. 66, p. 587-602, 2006.

SOARES, M. P. Verdes urbanos e rurais. Porto Alegre: Cinco Continentes, 1998. 242 p.

TANNUS, J. L S.; ASSIS, M. A.; MORELlATO, L. P. C. Reproductive phenology in dry and wet grassland in an area of cerrado at Southeastern Brazil, Itirapina - SP. Biota Neotropica, Campinas, v. 6. Disponível em: <http://www.biotaneotropica.org.br/v6n3/pt/abrstract? article+bn028060032006>. Acesso em: 20/09/2007.

ZAR, J. H. Biostatistical analysis. $3^{\text {rd }}$ ed. New Jersey: Prentice Hall, 1996. 662 p. 